\title{
RENTA BÁSICA UNIVERSAL: \\ CONSIDERACIONES DE DISEÑO Y RIESGOS \\ EN SU IMPLEMENTACIÓN
}

\section{UNIVERSAL BASIC INCOME: DESIGN CONSIDERATIONS AND RISKS IN ITS IMPLEMENTATION}

\section{Eduardo Garzón Espinosa}

Universidad Autónoma de Madrid, Madrid, España

eduardo.garzon@uam.es

Recibido: septiembre de 2020 Aceptado: noviembre de 2020

Palabras clave: Renta Básica Universal, protección social, condicionalidad.

Keywords: Universal Basic Income, social protection, conditionality.

Resumen: La propuesta de Renta Básica Universal cada vez es más conocida tanto en el terreno académico como fuera de él y eso le ha llevado a recibir cada vez más atención y también más críticas. Es difícilmente cuestionable que la Renta Básica Universal presenta ventajas muy importantes frente a otro tipo de prestaciones públicas de protección social: su cobertura alcanza a toda la población y la seguridad económica y libertad que brinda a sus beneficiarios permite que nadie se vea obligado a aceptar míseros y precarios trabajos para poder cubrir sus necesidades básicas. Además, todo ello se puede lograr con un coste económico asumible y a través de una aplicación relativamente sencilla y rápida (especialmente en comparación con muchas prestaciones sociales condicionadas). No obstante, la puesta en marcha de una Renta Básica Universal no está exenta de cuestionamientos ni de riesgos importantes a sopesar. Con este trabajo se pretende identificar y analizar algunos de ellos, con el objetivo último de superarlos para perfeccionar una medida que ya de por sí tiene un enorme potencial económico y social.

Abstract: The Universal Basic Income proposal is becoming more and more known both in the academic field and outside it and that has led it to receive more and more attention and also more criticism. It is hardly questionable that the Universal Basic Income has very important advantages compared to other types of public social protection benefits: its coverage reaches the entire population and the economic security and freedom it offers allows no one to be forced to accept poor and precarious jobs to cover their basic needs. In addition, all this can be achieved at an affordable cost and through a relatively simple and fast application (especially compared to many conditional social benefits). However, the start-up of a Universal Basic Income is not exempt from 
questions or important risks to take into account. The aim of this work is to identify and analyze some of them, with the ultimate goal of overcoming them to perfect a measure that already has enormous economic and social potential.

\section{l. Introducción}

La propuesta de Renta Básica Universal (RBU) cada vez es más conocida tanto en el terreno académico como fuera de él y eso le ha llevado a recibir cada vez más atención y también más críticas. La mayor parte de éstas tienen que ver con la imposibilidad o dificultad de financiarla, y también con los problemas de naturaleza ética o moral derivados de entregar una renta a todo ciudadano independientemente de su condición económica. No obstante, en este trabajo partimos de la premisa de que la financiación de la RBU es perfectamente factible y que entregar una renta a todo el mundo, incluyendo a los más adinerados, no supone un problema moral. En todo caso, el problema sería de carácter macroeconómico por las implicaciones que puede tener la inyección de renta a tanta gente en un contexto de relaciones laborales y económicas regidas por la lógica capitalista. Estas repercusiones, que han sido menos atendidas en el debate sobre la implementación de la RBU, son el objeto central del presente trabajo.

Puesto que hay variadas modalidades de rentas básicas ${ }^{1}$, para el análisis utilizaremos la que ofrece la Red de Renta Básica por ser la más conocida de todas y también porque cumple las características esenciales que toda prestación monetaria incondicional debe tener para ser

1. Ver Iglesias (2003) y Torres (2019). considerada como tal. La definición es la siguiente: "La renta básica es un ingreso pagado por el Estado, como derecho de ciudadanía, a cada miembro de pleno derecho o residente de la sociedad incluso si no quiere trabajar de forma remunerada, sin tomar en consideración si es rico o pobre o, dicho de otra forma, independientemente de cuáles puedan ser las otras posibles fuentes de renta, $y$ sin importar con quien conviva. En menos palabras: una renta básica es una asignación monetaria pública incondicional a toda la población" (Red Renta Básica, 2020).

También partiremos de la base de que dicha prestación monetaria se financia a través de una reforma fiscal del Impuesto de la Renta a las Personas Físicas (IRPF) al modo que proponen Jordi Arcarons, Antoni Domènech, Daniel Raventó y Lluís Torrens (Arcarons et al., 2017): un tipo fijo del $49 \%$ para todos los contribuyentes, de forma que junto con la renta de aproximadamente 650 euros mensuales ${ }^{2}$ en doce pagas el $20 \%$ más rico de la población tendría un resultado neto negativo mientras que el restante $80 \%$ se vería beneficiado en términos netos. Como será desarrollado posteriormente con mayor detalle, creemos que el modo de financiación de la medida es un aspecto esencial de la misma, pues dependiendo de la fórmula concreta el resultado final puede ser muy diferente. Hemos elegido esta propuesta concreta de financiación por ser, de nuevo, la más conocida de todas y también porque permite deshacernos de muchas de las críticas mencionadas con anterioridad con respecto al dilema moral que implicaría otorgar renta también a la población privilegiada.

2. En la propuesta mencionada la cantidad es de 622,5 euros. 
Por supuesto, también interpretamos que la meta que se pretende alcanzar con la RBU es la de mejorar la calidad de vida de la población manteniendo el mismo nivel del Estado de Bienestar que existe en la actualidad. Por lo tanto, nos alejamos de la mencionada amenaza que podría suponer la implementación de la RBU para las prestaciones públicas y sociales conquistadas durante el siglo XX (Navarro, 2018; Noguera, 2000).

A partir de estos mimbres conceptuales desarrollamos una crítica a la RBU que girará en torno a tres pilares que se abordarán en tres epígrafes distintos. El primero tiene que ver con la pertinencia de aprobar una RBU como respuesta a la robotización y mecanización de los procesos productivos -que supuestamente estarían reduciendo la necesidad de mano de obra. El segundo está relacionado con la supuesta incondicionalidad de la RBU, pues se argumentará que en función del tipo de implementación que se aplique dicha característica puede quedar en entredicho. En el tercero se presentan varios riesgos de carácter macroeconómico (pérdida de producción, tensiones inflacionistas, subordinación a los poderes de mercado...) asociados a la implementación de la medida. En el último epígrafe se resumen las conclusiones y se reflexiona sobre una posible forma de mejorar la RBU para reducir muchos de los riesgos presentados a lo largo del trabajo.

\section{2. ¿Un futuro sin empleo?}

Existe una idea más o menos generalizada en torno al futuro de nuestras economías capitalistas: habrá mucho menos empleo que en la actualidad. Algunos creen incluso que el número de puestos de trabajo podría reducirse a la mínima expresión en un futuro no muy lejano caracterizado por los nuevos adelantos tecnológicos y la robotización y mecanización de muchos procesos productivos. Frente a este hipotético horizonte en el que la fuerza de trabajo no será tan necesaria, suele esgrimirse que la RBU es la mejor política aplicable para asegurar un nivel de vida decente a todas esas personas que serán excluidas del mercado laboral.

Es fácil percibir en determinados sectores económicos que la instalación de máquinas 0 robots supone automáticamente el despido de muchos trabajadores. Ya en el siglo XVIII los artesanos luditas comenzaron a destruir telares industriales por considerarlos culpables de su pérdida de trabajo (Linton, 1992). La revolución agrícola del siglo XIX también provocó la sustitución de miles de trabajadores por, fundamentalmente, máquinas sembradoras (Jones, 2006). En la actualidad comprobamos conmovidos cómo multitud de empleos fabriles han desaparecido debido a la progresiva mecanización y robotización de muchas instalaciones. Y la amenaza no ha terminado: los taxistas y otros conductores temen el desarrollo y generalización de los vehículos que se conducen solos, los cajeros de los supermercados rezan para que no sean sustituidos por máquinas, los guardias de seguridad están preocupados por los impresionantes avances en sistemas informáticos de vigilancia, etcétera.

Pero ésta es solo una cara de la moneda, la más evidente, pero no podemos olvidarnos de la otra, aunque haya que esforzarse algo más para verla: la tecnología, incluyendo la robotización y mecanización, también permite que se creen nuevos puestos de trabajo. Ya una idea 
nos podemos hacer si comparamos la cantidad de empleos que hay en la actualidad con los que había, por ejemplo, en la época romana. Informáticos, científicos, biólogos, pilotos, conductores, electricistas, astronautas, ambientalistas, brókeres, mecánicos, técnicos de telecomunicaciones, jugadores de videojuegos, etcétera, son profesiones que no existían en la antigüedad y que son fruto del avance tecnológico. Es incontestable que en la actualidad hay muchísimos más tipos de empleos que décadas atrás.

Aunque la cantidad de profesiones no nos dice mucha de la cantidad total de trabajadores. Para abordar qué evolución ha experimentado el total de trabajadores a lo largo de la historia podemos realizar una primera aproximación muy tentativa atendiendo a los datos de la evolución de la población. En nuestro planeta hay hoy 7 veces más habitantes que en el año 1800 , y dos mil millones de personas más que hace tan sólo 25 años. En España la población actual casi triplica la de 1900, y tiene 10 millones de habitantes más que en 1980. Puesto que la cantidad de personas en el mundo ha tenido un crecimiento exponencial y las tasas de empleo no han cambiado radicalmente, hemos de deducir que la creación de puestos de trabajo también ha seguido un crecimiento importante a pesar de todo el avance tecnológico en los procesos productivos que han tenido lugar a lo largo de todo este tiempo.

No obstante, últimamente el acento no se suele poner tanto en el progreso tecnológico en general sino en la robotización y en el avance de la inteligencia artificial. Esto es precisamente lo que muchos han venido a denominar Cuarta Revolución Industrial, haciendo hincapié en que estos nuevos adelantos van a transformar el mundo laboral de una forma no vista hasta la fecha, de forma que lo que haya ocurrido en el pasado no nos puede dar pistas sobre lo que acontecerá en el futuro (Rabeh et al., 2017; Xu et al., 2018).

Es enormemente complicado -por no decir imposible- hacer previsiones fiables sobre el nivel de mano de obra que se requerirá en el futuro. De hecho, en la literatura actual podemos encontrar posicionamientos de todo tipo -e incluso enfrentados-: desde los que consideran que el volumen total de empleo va a menguar de forma importante (Pritchett, 2020; Rainie \& Anderson, 2017; World Economic Forum, 2017) hasta los que señalan que podría incluso aumentar precisamente gracias a dichos adelantos tecnológicos (Autor, 2015; Nübler, 2016; Stewarts et al., 2017).

En este último caso se suele señalar que la destrucción de empleo originada por la mecanización y robotización es compensada de sobra con la creación de otros puestos de trabajo. Los trabajos que se pierden serían los más rutinarios, duros, repetitivos, peligrosos y aburridos, ya que serían los más susceptibles de ser realizados por una máquina o robot. En cambio, los que se ganarían son los más artísticos, los más creativos y los relacionados con los cuidados, la tecnología y el conocimiento. La explicación reside en que la tecnología abre nuevas posibilidades de trabajo, permite generar más diversidad de riqueza y regala más tiempo libre al ser humano. Por eso, entre otras cosas, buena parte de las nuevas ocupaciones estarían relacionadas con el ocio y los cuidados. En otras palabras: aunque la robotización destruyese puestos de trabajo en muchos sectores económicos, permitiría la creación de muchos más en otros. Acorde a este planteamiento el efecto resultante podría ser muy positivo porque no sólo incrementaría la cantidad de empleo 
neto, sino que nos liberaría a los humanos de los trabajos más duros y peligrosos al mismo tiempo que nos permitiría disfrutar de nuevas y mejores posibilidades de ocio, cuidados, cultura y conocimiento. En cualquier caso, el debate está servido

Lo único que sí parece claro hoy en día es que, de momento, elevados niveles de robotización no están reñidos con tasas de desempleo muy reducidas. Acudiendo a los datos de densidad robótica (número de robots industriales en relación con el número de trabajadores industriales) de la Federación Internacional de Robótica y las tasas de paro de economías nacionales recogidas por el Banco Mundial, comprobamos que los países más robotizados son precisamente los que menos paro sufren. Corea del Sur, Singapur, Japón y Alemania son los países con más robots y al mismo tiempo los que disfrutan de tasas de desempleo más reducidas, inferiores al 5\% de la población activa. También podemos observar cómo no parece existir ninguna relación clara entre paro y robotización, pues países con similares niveles de robotización presentan tasas de paro muy dispares (Garzón, 2017). Otro análisis empírico señala en la misma dirección: desde el año 2000 hasta el año 2008 Corea del Sur, China y Brasil multiplicaron varias veces el número de robots utilizados en sus economías y el empleo creció en todos ellos con bastante intensidad (Gorle \& Clive, 2013). Esto nos viene a decir algo que, por otro lado, era de esperar: el número de robots instalados es solamente un factor explicativo -entre muchos- del desempleo (en uno u otro sentido), y no tiene por qué ser el más importante.

Resulta también interesante destacar una restricción importante al proceso de robotización y mecanización de las actividades productivas que desgraciadamente suele pasar desapercibida en este tipo de análisis: la escasez de materias primas que sustentan dicha transformación. En el campo de investigación de los vehículos eléctricos ya se ha puesto de manifiesto que materiales indispensables para su fabricación como el cobalto, el níquel, el manganeso y el neodimio se encuentran en nuestro planeta en cantidades insuficientes para la sustitución o conversión de la flota de energía fósil actual a una de suministro eléctrico (de la Torre et al., 2019; Glencore, 2018). Puesto que robots de cualquier tipo tienen una demanda de materias primas similar, parece lógico deducir que no es posible sustituir todo el actual trabajo humano por máquinas, ni siquiera llegar a niveles elevados en dicha sustitución -de ahí que muchas propuestas sobre modelos económicos futuros se centren en el retroceso en dicho consumo de recursos naturales (Latouche, 2006; Taibo, 2019).

En cualquier caso, todos estos análisis sólo tienen en cuenta la creación de puestos de trabajo por parte de un sector privado que, por definición y necesidad, busca la rentabilidad económica. Si a los empresarios les sale más rentable adquirir máquinas y robots que contratar trabajadores, es probable que la cantidad total de empleo tienda a menguar. No obstante, este criterio no nos sirve para analizar la contratación de trabajadores en el sector público ni en el sector privado no capitalista, pues ninguno de ellos se rige por la lógica de la rentabilidad económica sino que lo hace por otros objetivos como la utilidad social o el interés general. Que no vaya a haber empleo de naturaleza privada en un futuro no quiere decir que no vaya a haber necesidades sociales, ecológicas y de otro tipo por cubrir. Como sociedad necesitamos realizar y aumentar actividades cruciales para nuestro bienestar 
social y ecológico que hoy día no se llevan a cabo: necesitamos que se incrementen y mejoren los cuidados a la infancia y a la dependencia, los servicios educativos y los psicológicos, los cuidados a la fauna y a la flora y al medioambiente en general, e incluso los servicios culturales, de ocio y entretenimiento. Todo ello nos permitiría mejorar nuestra calidad de vida y la de la naturaleza, y además son precisamente actividades que por su naturaleza son diff́cilmente susceptibles de ser realizadas por máquinas o robots. Que a los agentes económicos privados capitalistas no les salga rentable atender esas necesidades no implica que no pueda hacerlo el sector público o el sector privado sin ánimo de lucro.

En definitiva, no es seguro que nos estemos encaminando hacia un horizonte en el que la necesidad de trabajo humano escasee. Y, aunque así fuese, sólo ocurriría en el ámbito del sector privado capitalista, pues al margen de él se podrían generar tantos empleos como fuesen necesarios para atender todas las necesidades de naturaleza social y ecológica que existirán (probablemente más graves que las actuales debido al desafío climático actual). Por eso carece de solidez justificar la implementación de la RBU como medio para garantizar un nivel de vida mínimo a todas las personas que quedarían excluidas del mercado laboral, porque esto último es sencillamente un escenario dudoso y, además, perfectamente evitable.

\section{3. ¿Es la renta básica universal verdaderamente incondicional?}

Por definición la Renta Básica Universal es una prestación de carácter incondi- cional, esto es, que todo ciudadano de pleno derecho es beneficiario de la misma independientemente de su condición particular. De esta forma, nadie quedaría excluido de recibir la prestación monetaria. Además, puesto que la cuantía sería fija para todo el mundo, tanto la persona de mayor renta como la de menor renta se verían beneficiadas de igual forma. Sin embargo, dependiendo de cómo se financie la medida este efecto podría ser distinto, pues podría ocurrir que algunos agentes económicos tuviesen que aportar más renta para financiar la medida que la que recibirían por ella, sufriendo un efecto neto negativo; y al revés, algunos podrían aportar menos que lo que finalmente recibirían, disfrutando de un efecto neto positivo. En consecuencia, aunque la propia prestación monetaria de la RBU fuese igual para todo el mundo, el efecto neto final podría no serlo.

Si para financiar el coste de la RBU la administración pública correspondiente recurriese a emisión monetaria o de bonos públicos, entonces el efecto neto sería exactamente igual que el efecto bruto, y todo beneficiario se vería beneficiado en la misma cuantía. No obstante, si la financiación se articulase a través de una reforma fiscal como la propuesta por Arcarons et al. (2017) cada beneficiario vería en sus cuentas personales un efecto neto distinto. Recuérdese que, acorde a los propios cálculos de sus proponentes, el segmento compuesto por el 20\% más acaudalado de la población aportaría más a las arcas públicas que lo que recibiría por la asignación monetaria de la RBU, mientras que ocurriría lo contrario con el resto de beneficiarios.

Así las cosas, habría motivos para hacernos la siguiente pregunta: ¿la RBU financiada de esta forma se puede con- 
siderar incondicional? Y es que, aunque la prestación monetaria asignada por la RBU sería incondicional, el efecto neto quedaría condicionado a la renta. Aunque la persona con mayor renta de la muestra recibiese 650 euros del Estado, al mismo tiempo estaría pagando en impuestos bastante más de 650 euros, ergo esta persona se encontraría finalmente en peor situación económica tras ejecutarse la RBU. Al mismo tiempo, la persona con menor renta de la muestra no pagaría impuestos pero recibiría una renta de 650 euros, mejorando por lo tanto su situación económica. Por lo tanto, el resultado neto de cada persona tras la ejecución de la RBU dependería de la renta inicial, ergo su situación económica final estaría condicionada a su renta. El $20 \%$ de la población más adinerada vería perjudicada su posición económica, mientras que el $80 \%$ restante la vería beneficiada. La clave del asunto está en poner el foco de atención en la renta final resultante tras aplicarse la herramienta de financiación mencionada, y no en la cantidad monetaria asignada como RBU (ya que ésta no es posible sin aquella).

Una réplica habitual a esta puntualización se basa en resaltar que las personas del segmento superior de la renta también se benefician de la RBU porque, en el hipotético caso de que pasaran a estratos inferiores como resultado de sufrir una caída importante en los ingresos, el efecto neto pasaría a ser positivo (Arcarons et al., 2017; Pérez, 2015). Sin embargo, esta argumentación no invalida que haya siempre un estrato de la población que salga perdiendo con la ejecución de la RBU, aunque ese estrato no incluya siempre a las mismas personas, ni invalida, por lo tanto, que el efecto económico de una RBU financiada a través la reforma fiscal dependa de los ingresos iniciales.
Lo que se trata de señalar aquí es que la fórmula de financiación puede convertir una RBU de naturaleza incondicional en una de naturaleza condicional a la renta y que, por lo tanto, podría provocar que no se distanciase mucho de cualquier prestación monetaria condicionada al cumplimiento de determinados umbrales de renta. La diferencia radicaría en los estratos afectados por la medida: en el caso de una renta condicionada la población que vería alterada su renta sería solamente la que recibiría el ingreso ${ }^{3}$, que raramente supondría el $80 \%$ como en el caso de la RBU.

Es frecuente escuchar que, al margen de lo señalado, habría una diferencia notable entre una RBU y una condicionada a la renta: los costes de administración, que sería mucho menores en el primer caso. No obstante, ni dichos costes son tan reducidos en el caso de una RBU, ni tienen por qué ser elevados en el caso de una renta condicionada si su diseño es adecuado (de Wispelaere \& Stirton, 2011, 2012; Noguera, 2015).

En primer lugar, en una RBU financiada a través de la reforma fiscal mencionada, todo el mundo tendría que declarar la renta que recibiese cada año, pues de lo contrario no podría aplicársele el tipo fijo del $49 \%$ a sus ingresos. Esto provocaría que el coste administrativo de una RBU aumentase con respecto al coste actual de declaración de la renta, pues hoy día no toda la población está obligada a presentarla (sólo lo hacen unos 19 millones de un total de 47). En cambio, cualquier renta condicionada gestionada a través

3. Aunque evidentemente también dependería de la fórmula de financiación empleada, pero al necesitar una movilización menor de recursos es de suponer que también sería menor el estrato de población afectada negativamente. 
también del impuesto sobre la renta (tras la declaración de ingresos, si fuese necesario, el Estado aportaría la cantidad necesaria para alcanzar el mínimo de renta establecido) requeriría menos costes administrativos porque sólo tendrían que declarar sus ingresos los afectados, no toda la población. Es más costoso y farragoso detraer recursos del 20\% más rico para transferirlo al $80 \%$ más pobre como ocurre en una RBU que detraer recursos, por ejemplo, del $5 \%$ más rico y transferirlo al $20 \%$ más pobre como ocurre en una prestación condicionada a la renta (Garzón, 2016; Noguera, 2015).

En segundo lugar, en una RBU todas las personas del país deberían tener una cuenta bancaria donde recibir cada mes la cuantía monetaria, o tendrían que ir alguna sucursal bancaria a cobrarla en mano, y el Estado debería tener registro de todo ello. Esto exige ya un coste administrativo superior al actual (aunque sea reducido). En tercer lugar, como la tentación a declarar menos renta de la realmente obtenida no sólo seguiría existiendo sino que se intensificaría por la aparición de la RBU (que obligaría a declarar sus rentas a todos los residentes y no sólo a una parte y porque es muy sencillo y atractivo añadir a la RBU un ingreso en negro), si el Estado no quiere que el fraude fiscal se dispare y se cometan abusos importantes necesariamente tendría que incrementar los recursos y medios destinados a controlar el fraude fiscal. Es decir, más gasto administrativo y de control.

En definitiva, la RBU sólo sería verdaderamente incondicional si se financiase a través de emisión monetaria o de endeudamiento, ya que si lo hiciese a partir de una reforma fiscal que detrajese sobre todo recursos de los más acaudalados, estos dejarían de ser beneficiarios netos de la prestación y, por lo tanto, quedaría violada la incondicionalidad de la medida, provocando que la RBU no se distanciase mucho de una prestación condicionada a la renta.

\section{Riesgos}

Al margen de lo cuestionable que puede ser justificar la implementación de la RBU en virtud de un hipotético futuro caracterizado por menos necesidad de trabajo y de lo cuestionable que puede ser su carácter incondicional, la medida presenta otros inconvenientes de naturaleza muy distinta. Estos inconvenientes tienen que ver con la alteración que podría suponer su aplicación sobre el modelo económico actual, y con cómo este efecto, lejos de resultar beneficioso para los ciudadanos más desprotegidos, podría generarles problemas de cierta importancia.

\section{4.l Tensiones inflacionistas y subvenciones a empresas}

Es bien sabido que muchas personas trabajan en la actualidad en empleos precarios con malas condiciones laborales y salariales por una cuestión de necesidad económica: o aceptan dichos empleos o se ven abocados a no disponer de ingresos suficientes para atender las necesidades más básicas. Una de las ventajas de la RBU más señaladas por sus proponentes es que supondría un colchón de seguridad económica para estas personas y las liberaría de tener que aceptar dichos empleos. Muchos de estos trabajadores abandonarían sus puestos de trabajo para siempre y se dedicarían a otros menesteres, pero muchos otros se verían con 
mayor poder de negociación y reclamarían mejoras en las condiciones laborales. Frente a la amenaza de quedarse sin trabajadores, a los empleadores no les quedaría más remedio que ceder a sus exigencias. El resultado final no podría ser más positivo: libertad de decisión a la hora de trabajar en cualquier emleo, mayor poder de negociación, mejoras laborales y fin de los empleos precarios. El único elemento negativo de todo este asunto sería que los empresarios tendrían menor margen de beneficio; sin duda un coste que merecería la pena asumir.

No obstante, en ese razonamiento se están dando por válidas muchas premisas que en realidad no están aseguradas. Por un lado, hay motivos distintos a la necesidad económica que llevan a muchas personas a aceptar empleos con malas condiciones laborales, de forma que ni siquiera con un colchón de seguridad económica se verían animados a abandonarlos 0 a exigir mejoras laborales. Por otro lado, los empresarios no siempre tienen la opción de mejorar las condiciones laborales reduciendo su margen de beneficio, por lo que frente a las exigencias laborales podrían reaccionar elevando los precios de los productos o directamente cerrando su negocio. Abordemos estos dos puntos con más detenimiento.

Partamos en primer lugar, y de nuevo, de una RBU financiada como sugieren Arcarons et al. (2017). En este caso, y como ya se ha señalado, existe un nivel de renta que separa a los que se ven perjudicados en términos netos por ella (el 20\% de mayor renta) de los que se ven beneficiados (el restante $80 \%$ ). Utilizando el mismo cálculo que se expone en Garzón (2015) para el año fiscal 2019, obtendríamos que ese nivel se situaría en torno a los 1.900 euros brutos mensuales. A partir de ello analizamos diferentes situaciones en función de la renta obtenida.

Para aquellas personas que no ingresan absolutamente nada es evidente que la RBU tendría un efecto enormemente positivo: en vez de recibir 0 euros pasarían a recibir unos 650 euros cada mes. Además, puesto que estas personas no trabajan, no se produce ninguna alteración en el mercado laboral. En consecuencia, una RBU para aquellos que no ingresan nada sólo depara efectos positivos.

Ahora bien, con las personas que reciben un salario o un ingreso por su trabajo no ocurre lo mismo. De momento ignoraremos los ingresos que no se deriven del trabajo (alquileres, dividendos, intereses, etcétera) y nos centraremos únicamente en los que emanan del trabajo (asalariados y autónomos, fundamentalmente). Como es obvio, al recibir un ingreso fijo independientemente de que se trabaje 0 no, uno podrá decidir si le merece la pena seguir trabajando o si, por el contrario, le resulta preferible abandonar ese empleo. Se trata de una decisión personal que tiene un carácter enormemente subjetivo: las situaciones en las que se encuentran los trabajadores y trabajadoras son enormemente diversas, amén de que las personas tienen preferencias muy diferentes entre sí, y lo que haría un individuo en concreto no tiene por qué ser lo mismo que lo que haría otro en la misma situación. Es decir, no tenemos forma humana de estimar con precisión qué harían estas personas una vez recibiesen la RB. Pero sí podemos hacernos una idea aproximada: cabe esperar que la decisión de abandonar o no el puesto de trabajo dependa de tres variables que están muy interrelacionadas: 1) la satisfacción personal que otorgue la realización de las actividades 
asociadas al empleo en cuestión, 2) el margen y predisposición que tenga el empleador de aumentar la remuneración con el objetivo de que el trabajador no abandone el empleo, y 3) cuánto dinero se perdería con la renuncia al puesto de trabajo.

Si la actividad es desagradable y/o sufrida, la persona en cuestión tendrá interés en abandonar el empleo a no ser que la remuneración se eleve tanto que compense llevarla a cabo a pesar de los inconvenientes. Pero, si tenemos en cuenta que la alternativa de no trabajar te garantiza un ingreso mínimo de unos 650 euros mensuales, y que además te otorga la posibilidad de dedicarte a cualquier otra cosa más agradable (ya sea descansar, estudiar, investigar, realizar actividades artísticas, buscar otro empleo, etcétera), ¿a partir de qué cuantía monetaria una persona aceptaría realizar una actividad que no le satisface nada? ¿Por cuánto dinero extra estaría la gente dispuesta a seguir en un empleo que te obliga a madrugar mucho, trabajar durante numerosas horas diarias, soportar condiciones adversas, realizar un esfuerzo físico y/o psicológico importante, y que no te depara apenas ninguna satisfacción? Es difícil saberlo, pero no parece descabellado asumir que prácticamente la única forma de compensar ese esfuerzo en la mayoría de los casos sería si se recibiese al menos el doble de esa cantidad: unos 1300 euros mensuales netos aproximadamente (lo cual le supondría al empleador un incremento muy notable en el coste laboral). En este caso es probable que el trabajador aceptase seguir realizando el mismo trabajo que no le agrada. Esto no quita que muchas personas pudiesen continuar con sus empleos a pesar de recibir menos dinero, ni que otras lo pudiesen abandonar incluso aunque cobraran más de esa cantidad, pero al menos nos sirve para hacernos una idea aproximada.

Ahora bien, ¿todos los empleadores pueden permitirse el lujo de elevar tanto los salarios? Es evidente que no. Algunos sí podrán, especialmente los pertenecientes a grandes empresas con grandes márgenes de beneficio, como por ejemplo las de telecomunicaciones (podrían pagar más a los teleoperadores, por ejemplo ${ }^{4}$ ) o las grandes superficies (en el caso de empleados de bajo rango). Pero no ocurriría lo mismo con empresas y negocios más pequeños y menos rentables: establecimientos comerciales, hostelería, explotaciones agrícolas y ganaderas, personal doméstico, transporte, servicios profesionales, servicios de mantenimiento inmobiliario, etcétera.

Podemos imaginar que hay autónomos y pequeños empresarios que realizan jornadas maratonianas (y que seguiremos considerando no agradables) en sus negocios para terminar ingresando menos de 1.300 euros mensuales. ¿Qué pasaría con todos estos negocios si se implantara una RBU de unos 650 euros al mes? No parece exagerado imaginar que muchísimos autónomos y asalariados dejarían de realizar sus actividades. No podemos perder de vista que la cantidad de trabajadores que ingresan menos de esa cantidad es muy importante: según la Encuesta de Estructura Salarial que realiza el Instituto Nacional de Estadística, en 2018 el 14,10\% de todos los asalariados ingresaron menos

4. Que, debido a que precisamente en este tipo de empleos se pueden y suelen contratar a personas no residentes en el territorio español porque están dispuestos a cobrar menos, abre un nuevo debate. Si la RBU no llegara a estas personas (y es de suponer que no), buena parte de estos empleos -si no todos- serían acaparados por trabajadores de otros países y por lo tanto los empleadores no tendrían por qué aumentar los salarios. 
del salario mínimo, que ese año fue de 10.302 euros anuales (858,5 euros en doce pagas), por lo que podemos deducir que la cantidad de personas ingresando menos de 1.300 euros mensuales es mucho mayor. Si buena parte de estas personas decidiesen abandonar sus actividades, ello tendría consecuencias muy importantes, no sólo de forma directa sino también indirecta: esos negocios hoy día compran muchos productos y servicios a otras empresas (provisión de mercancías, contrato de servicios profesionales -fiscales, jurídicos...- etcétera), de forma que disminuirían también los ingresos y beneficios de todas esas empresas que tenían vínculos con los negocios que desaparecerían por el efecto de la RBU, produciéndose así un efecto dominó que acabaría afectando a una buena parte de la estructura empresarial y productiva de la economía española. Se ofertarían menos bienes y servicios, y se produciría menos renta y riqueza. Una renta y riqueza que, por cierto, es el origen y la base que financia la RBU, ya que dicho flujo monetario es financiado gracias a los impuestos de las rentas de los que sí trabajan.

Pero hay más. Cuando la oferta de bienes y servicios disminuye (por el efecto recién mencionado) y la capacidad adquisitiva de la población aumenta por el efecto de la RBU en las capas de menos recursos, se crean todas las condiciones para que se generen tensiones inflacionistas. Es decir, por la ley de la oferta y la demanda, más dinero -o el mismo- que antes dedicado a comprar menos productos y menos servicios que antes tiende a provocar que los vendedores de esos bienes y servicios se vean tentados a aumentar los precios para aprovecharse de esa nueva situación en la que tienen menos competidores. $Y$ no sólo eso: puesto que la reducción en la oferta de esos bienes y servicios se produce únicamente en el territorio español, la única posibilidad de satisfacer toda la demanda será a través de mayores compras de productos extranjeros, lo cual tendría como consecuencia un aumento del déficit comercial y por lo tanto un incremento en el endeudamiento exterior de la economía española. En resumen: hay sospechas fundamentadas de que la aplicación de una RBU podría provocar un incremento en el ritmo de la inflación y en el -ya elevadísimo- endeudamiento exterior de la economía española.

Ahora exploremos qué ocurriría con los puestos de trabajo que no son desagradables y que por lo tanto cabría pensar que no serían rechazados por sus ocupantes. Con respecto a aquellos en los cuales la nueva remuneración debido a la RBU sería inferior a la actual (a partir de los 1.900 euros brutos mensuales; es decir, los que saldrían perdiendo en términos netos con la aplicación de la medida), cabe esperar que no ocurriría nada relevante, ya que el aumento en la presión fiscal no sería elevado ${ }^{5}$. Es decir, nada muy diferente a lo que ha ocurrido en muchas ocasiones cuando se han aumentado los tipos del IRPF. En cambio, para aquellas personas que ingresan menos de 1.900 euros brutos mensuales la cosa puede ser diferente.

Imaginemos el caso en el que un trabajador o trabajadora, sin intención de abandonar su empleo (ya sea porque está satisfecho/a, o porque le repara perspectiva profesional, o porque no quiere dedicarse a otra cosa, etcétera), tenga un salario de 1.000 euros brutos mensuales. En la actualidad, su ingreso neto sería de 1.000 euros, y tras la puesta en marcha

5. Ver, a modo de ejemplo ilustrativo, los cálculos de Garzón (2015). 
de la RBU (incluyendo el pago del IRPF con el tipo del 49\%) su ingreso pasaría a ser de unos 1.100 euros netos. En este caso, el empleador tendría incentivos a pagar menos por salario, ya que aunque le pagase 900 euros en vez de 1.000 , el ingreso final del trabajador sería 1050 gracias a la RBU, todavía superior a los 900 que ingresaba antes, de forma que ganaría tanto el empleador como el empleado. Lo mismo podría ocurrir para alguien que cobrase más dinero, como 1.300 euros brutos mensuales, ya que aunque el empleador redujese el salario a 1.100, el trabajador acabaría recibiendo más de lo que ingresaba sin la aplicación de la RBU.

Es decir, en este tipo de situaciones en las cuales el empleado no tiene interés en abandonar el puesto de trabajo, se corre el riesgo de que los empresarios aprovechen la existencia de la RBU para pagar menos por salarios. El dinero que recibe el trabajador ya no sólo sería pagado por el empresario, sino también por el sector público. La consecuencia que esto tendría es que el Estado estaría subvencionando a estas empresas a través de la RBU. Y si bien es cierto que sería conveniente que algunas empresas recibiesen ayudas públicas, también es cierto que no ocurre lo mismo con todas. Las subvenciones públicas a empresas deberían darse de forma diferenciada, atendiendo a las particularidades de cada una, y no de forma descontrolada como ocurriría en estos casos debido a la RBU. En resumen, en este tipo de situaciones no sólo el trabajador no ganaría poder de negociación frente a su empleador, sino que éste acabaría pagando menos en concepto de salarios, aumentando su margen de beneficio por el camino ${ }^{6}$. Es decir, ocurriría precisa-

6. Téngase en cuenta, además, que los empleadores que ingresasen menos de 1.900 euros al mes gana- mente lo contrario de lo que defienden los defensores de la RBU.

En consecuencia, y teniendo en cuenta los dos efectos mencionados (abandono de los puestos de trabajo desagradables y/o de menor productividad, y ayudas públicas a determinadas empresas) tenemos como resultado final algo que seguramente no busca ningún defensor de la RBU: las empresas que no pudiesen incrementar de forma suficiente los salarios o bien incrementarían los precios (originando tensiones inflacionistas) o bien desaparecerían $^{7}$, mientras que otras (de las cuales muchas seguramente sí podrían pagar más salarios) serían subvencionadas por el Estado. Perjuicio para algunas -probablemente pequeñas- empresas; ayudas para otras que quizás no las necesitasen ni mereciesen. A lo que habría que sumar el negativo impacto macroeconómico sobre la estructura productiva que tendría la desaparición de muchos negocios: menor producción, efecto recesivo, tensiones inflacionistas, déficit comercial, endeudamiento externo, etcétera.

En efecto, tal y como prevén muchos defensores de la RBU, la implementación de la medida cambiaría notablemente las relaciones de los agentes económicos. Pero lo que se ha querido poner de manifiesto aquí es que esos cambios podrían tener más efectos perniciosos que beneficiosos sobre la estructura empresarial y productiva de la economía al generar importantes desequilibrios económicos. La RBU se ajusta bastante bien para personas que no reciben ingresos pero no tan bien para aquellos trabajadores y trabaja-

rían no sólo por el efecto de pagar menos salarios, sino también por el efecto de la propia RBU.

7. Lo que probablemente ocurriría con más intensidad en negocios de reducida dimensión. 
doras que se sitúan en el extremo inferior del mercado laboral al alterar directamente el conflicto capital-trabajo, que es el núcleo de cualquier economía capitalista.

\subsection{Subordinación a los poderes de mercado}

Al ser una prestación de carácter monetario, la RBU sólo puede ser de utilidad a sus beneficiarios a través del mercado capitalista. El Estado entrega una renta a los ciudadanos para que estos compren los bienes y servicios que quieran siempre que hayan sido producidos anteriormente y siempre que estén disponibles en el mercado y a precios asequibles. En consecuencia, la RBU no puede satisfacer las necesidades de los ciudadanos por sí misma, sino que necesita que la economía funcione adecuadamente para que el sector privado produzca todo lo que demande la ciudadanía. Esto es muy diferente de lo que ocurre con algunas de las prestaciones clave del Estado Social: educación y sanidad, que son ámbitos en los que el Estado ofrece un servicio directamente al beneficiario, sin que medie prestación monetaria ni la lógica de mercado por ningún sitio. En este caso el Estado se encarga de satisfacer la necesidad de la ciudadanía de forma directa, sin necesidad de que el sector privado tenga que producir bienes y servicios y ponerlos a la venta a un precio asequible.

La diferencia no es baladí: si por algún motivo el sector privado no es capaz o no está dispuesto a ofrecer en condiciones razonables los productos que necesitan los ciudadanos, entonces el efecto RBU se disiparía o incluso llegaría a desaparecer. Hay varias posibilidades de que esto ocurra y algunas precisamente pueden ser el resultado de poner en funcionamiento la RBU. Una de ellas ya ha sido mencionada en el epígrafe anterior: frente a la presión por incrementar los salarios (debido al mayor poder negociador de los trabajadores beneficiados por la RBU), los empresarios podrían cerrar sus negocios o incrementar el precio de sus productos para no perder margen de beneficio, teniendo como resultado que algunos productos serían retirados de la venta mientras que otros directamente dejarían de ser tan asequibles (disipando la capacidad adquisitiva de la RBU). En consecuencia, la propia ejecución de la RBU podría poner en riesgo que el sector privado ofreciese sus productos en la misma cantidad y condiciones que antes de que dicha política fuese activada, impidiendo así que el Estado pudiese atender las necesidades de la ciudadanía tal y como estaba previsto.

Otra posibilidad está vinculada al intento, por parte de los vendedores de productos, de beneficiarse parcialmente de la mejora adquisitiva de los compradores a través de incremento de los precios. Conscientes de que la ciudadanía tendría más capacidad económica gracias a la RBU, los vendedores podrían verse tentados a incrementar ligeramente el precio de sus productos con el convencimiento de que serían vendidos igualmente, aumentando así su margen de beneficio y reduciendo el potencial de la RBU. De nuevo estaríamos frente a un caso en el que el sector privado, gracias a su privilegio en la producción y venta de bienes y servicios, podría con sus acciones anular o mitigar la satisfacción de las necesidades que persigue el Estado con la aprobación de la RBU. Y todo ello porque la naturaleza monetaria de la prestación provoca que los ciudadanos queden supeditados a los mecanismos de mercado. 
La última posibilidad que aquí apuntaremos es que el sector privado quedase incapacitado para proveer suficientes bienes y servicios, ya fuese por el surgimiento de una pandemia, por una catástrofe natural o bélica, o incluso por que se decidiese a paralizar la producción de bienes y servicios como forma de boicotear la propia medida de la RBU o por cualquier otro motivo. En todos estos casos el Estado perdería su capacidad de garantizar la satisfacción de las necesidades de la ciudadanía únicamente por estar supeditado al funcionamiento del sector privado al haber provisto solamente una renta monetaria.

Por últimos, es importante resaltar que, al tratarse de una cuantía homogénea para todo el mundo, la RBU no distingue el nivel de vida que existe en cada región en la que vive su beneficiario. Evidentemente no es lo mismo disponer de 650 euros en pleno centro de la capital del país que hacerlo en un pequeño pueblo rural de una provincia de interior: en el primer caso la RBU permitiría adquirir menos bienes y servicios que en el segundo. Esto puede conducir a que una RBU de 650 euros quizás permitiría satisfacer las necesidades más básicas (que es el objetivo principal de la medida) en un caso, pero podría no lograrlo en otro, o incluso resultar relativamente generosa en un tercer caso. Es cierto que este defecto de la medida podría considerarse menor, especialmente comparado con las ventajas que podría deparar, pero en cualquier caso también es cierto que debe ser tenido en cuenta.

\subsection{Libertad sin compromisos}

Uno de los propósitos más importantes de la RBU es dotar de mayor libertad a sus beneficiarios para que puedan organizar- se sus vidas de la mejor forma posible. En efecto, cuando una persona recibe un colchón incondicional y perpetuo de unos 650 euros mensuales queda liberado de la necesidad de buscarse la vida a cualquier precio y de cualquier forma. Al mismo tiempo, uno dispone de más tiempo y margen de maniobra para hacer lo que realmente quiere hacer, ya sea destinar buena parte de su tiempo al ocio, a la cultura, a formarse académicamente, a buscar un mejor empleo o incluso a crearlo él mismo.

Los defensores de la RBU suelen ser muy optimistas con respecto a cómo la ciudadanía utilizaría esa mayor libertad, pues presuponen que en algún momento invertirían su tiempo y energías en realizar actividades que redunden en el interés general. El que esto escribe no tiene duda de que muchas personas así lo harían, pero tampoco de que muchas otras no. No podemos perder de vista que vivimos en una sociedad capitalista en la que imperan los valores individualistas y consumistas, en el que los mensajes más emitidos invitan a la gente a trabajar y a consumir con el objetivo principal de incrementar la rentabilidad de las empresas y no el de mejorar la calidad de vida de la gente ni del medio ambiente. La cultura de apoyo desinteresado al prójimo está mucho menos visible en nuestras sociedades actuales, y eso importa a la hora de imaginar cómo puede canalizarse la libertad de los beneficiarios de la RBU.

No se trata de pensar que el ser humano es egoísta y perezoso por naturaleza, sino de tener presente que nuestras instituciones colectivas nos empujan a serlo en pro de un adecuado funcionamiento del sistema capitalista. En consecuencia, no es descabellado pensar que buena parte de todas aquellas personas que recibirían 
la RBU acabasen nutriendo al sistema a partir de más consumo irresponsable e insostenible y carente de todo tipo de valores sociales y ecológicos. Éste es uno de los riesgos que tendría implementar una RBU sin ningún tipo de medida paralela que buscase educar en unos principios y valores muy distintos de los que inoculan mayoritariamente nuestras sociedades.

\section{Conclusiones y reflexiones finales}

La RBU presenta ventajas incontestables frente a otro tipo de prestaciones públicas de protección social: su cobertura alcanza a toda la población y la seguridad económica y libertad que brinda a sus beneficiarios permite que nadie se vea obligado a aceptar míseros y precarios trabajos para poder cubrir sus necesidades básicas. Además, todo ello se puede lograr con un coste económico asumible y a través de una aplicación relativamente sencilla y rápida (especialmente en comparación con muchas prestaciones sociales condicionadas). No obstante, la puesta en marcha de una RBU no está exenta de cuestionamientos ni de riesgos importantes a tener en cuenta. Identificar y analizar algunos de ellos ha sido el objeto del presente trabajo.

En primer lugar, es muy cuestionable justificar la necesidad de la aplicación de la RBU alegando que nos enfrentamos a un futuro en el que las necesidades de trabajo van a ser mucho menores como consecuencia de la robotización y mecanización de muchas actividades económicas. Por un lado, acorde a la evidencia disponible no es seguro que nos estemos encaminando hacia un horizonte de esas características. Por otro lado, aunque así fuese, la falta de demanda de mano de obra sólo se daría en el ámbito del sector privado capitalista, mientras que los sectores público y privado no capitalista podrían contratar a todas las personas que quisiesen trabajar para atender todas las necesidades de naturaleza social y ecológica que sin duda existirán. Carece de solidez justificar la implementación de la RBU como medio para garantizar un nivel de vida mínimo a todas las personas que quedarían excluidas del mercado laboral, porque esto último es sencillamente un escenario dudoso y, además, perfectamente evitable.

En segundo lugar, si la RBU se financiase a través de una reforma fiscal progresiva que afectase negativamente en términos netos al $20 \%$ de los contribuyentes más acaudalados -como se recoge en la propuesta más conocida-, entonces quedaría en duda su naturaleza incondicional, pues ese estrato de la población no se vería beneficiado en última instancia por la medida. En consecuencia, una RBU de este tipo acabaría siendo -en cuanto a los efectos resultantes de su aplicación- condicional a la renta y no se distanciaría mucho de otro tipo de prestaciones que pretender abarcar sólo a una parte de la ciudadanía, aunque normalmente la cantidad de personas beneficiadas por ese tipo de prestaciones es notablemente inferior.

En tercer lugar, la heterogeneidad del mercado de trabajo, así como de las preferencias de los trabajadores, permite vislumbrar un amplio abanico de posibilidades de decisiones laborales y vitales una vez fuese aplicada la RBU. Algunas de ellas podrían redundar en beneficio de toda la sociedad, pero otras podrían repercutir negativamente en la cantidad de bienes y servicios producidos, en el ritmo de la inflación, e incluso en el saldo comercial 
y endeudamiento exterior de la economía. Además, no es descabellado pensar que en muchos casos la RBU actuase prácticamente como una subvención pública a muchas empresas. No está claro que los efectos negativos se antepusiesen a los positivos, pero en cualquier caso es un riesgo importante para sopesar.

En cuarto lugar, al ser la RBU una prestación exclusivamente monetaria, los beneficiarios sólo podrían satisfacer sus necesidades a través del mercado, comprando en él los bienes y servicios requeridos. Esto dejaría a la población en una situación de subordinación y dependencia frente a los poderes de mercado que, por motivos de incapacidad o de voluntad, podrían no producir ni vender en cantidades suficientes y/o en condiciones adecuadas lo que necesitase la población, reduciendo así el potencial y alcance de la RBU. Por último, en sociedades consumistas e individualistas como las actuales, la libertad otorgada por la prestación podría no canalizarse en una dirección adecuada para cubrir las necesidades sociales y ecológicas actuales y futuras.

Todos estos riesgos no deben verse como motivos para impugnar la esencia de la RBU sino como desafíos que deben ser superados para perfeccionar así la prestación. De hecho, creemos que buena parte de estos riesgos pueden ser mitigados notablemente con la introducción de dos modificaciones sustanciales a la medida.

La primera consistiría en diseñar la RBU para que dejase de ser exclusivamente monetaria y pasara a contemplar una parte en especie (retribución en bienes y servicios). En vez de percibir cada individuo 650 euros para comprar productos en el mercado, el Estado podría garantizar a cada persona determinados bienes y servicios considerados esenciales. Esto es precisamente lo que ocurre con la educación y sanidad públicas: el Estado no entrega dinero para pagar los servicios de educación y sanidad en el mercado, sino que ofrece la posibilidad de recibir esos servicios en centros sanitarios y educativos sin necesidad de que haya pago de por medio. Lo mismo podría ocurrir con una RBU que garantizase al ciudadano una vivienda, un consumo básico de energía, de transporte, de cuidados, de alimentación, de vestimenta, etcétera. No habría necesidad de utilizar esos 650 euros para alquilar una vivienda, comprar alimentos, comprar ropa, desplazarse, adquirir servicios de cuidados, etcétera, sino que simplemente por el hecho de ser ciudadano se tendrían garantizadas esas necesidades básicas. De esta forma se resolvería parte de los problemas que habíamos detectado: ya no se produciría discriminación por regiones con diferentes niveles de vida, porque todo el mundo podría cubrir las mismas necesidades independientemente del nivel de precios de cada región; y ya no se dependería tanto del adecuado funcionamiento del sector privado para atender las necesidades básicas.

La segunda modificación consistiría en acompañar la prestación económica con la posibilidad de realizar alguna actividad beneficiosa para la sociedad y el medio ambiente. No necesariamente como condición ineludible para recibir la prestación, sino como opción voluntaria para contribuir al interés general. La RBU por sí sola no puede asegurar que sus beneficiarios dediquen esfuerzos en mejorar su entorno social y ecológico, porque al mismo tiempo están recibiendo poderosas señales desde este sistema que los empuja, en muchas ocasiones, precisamente 
en una dirección opuesta. Por eso, podría ser buena idea complementar una RBU con la adquisición de responsabilidades y compromisos en relación con el cuidado de nuestro prójimo y de nuestra biosfera, con el objetivo de impregnar valores de responsabilidad democrática, colectiva, social y ecológica. La clave del asunto es que, aunque todo el mundo desease hacer algo positivo por su comunidad, es muy probable que no supiesen por dónde empezar ni cómo organizarse adecuadamente para ello. No sólo es necesario tener voluntad y deseo, sino también iniciativa y desenvolvimiento. Por todo ello, mucho mejor que confiar en la iniciativa individual de cada uno de los ciudadanos y esperar a que se pongan en marcha es planificar y programar las actividades que podrían llevar a cabo.

En definitiva, buena parte de los riesgos asociados a la implementación de una RBU podría ser mitigados modificando sustancialmente algunos elementos de dicha prestación. No todos los inconvenientes serían resueltos, y las modificaciones podrían acarrear una complejidad nada desdeñable, pero muy probablemente mereciese la pena embarcarse en dicho proyecto con el fin último de perfeccionar una medida que ya de por sí tiene un enorme potencial económico y social.

\section{Bibliografía}

Arcarons, J., Raventós, D., \& Torrens, L. (2017). Renta básica incondicional. Una propuesta de financiación racional y justa. Ediciones del Serbal: Barcelona.

Autor, D. H. (2015). Why are there still so many jobs? The history and future of workplace automation. Journal of Economic Perspectives, 29 (3), 3-30. https:// doi.org/10.1257/jep.29.3.3 de la Torre, L., Álvarez, E., \& Espí, J. A. (2019). Protagonismo de las materias primas minerales en el desarrollo del vehículo eléctrico. Visión Industrial, 411, 99-112.

de Wispelaere, J., \& Stirton, L. (2011). The administrative efficiency of basic income. Policy and Politics, 39 (1), 115-132. https://doi. org/10.1332/030557311X546352

de Wispelaere, J., \& Stirton, L. (2012). A disarmingly simple idea? Practical bottlenecks in the implementation of a universal basic income. International Social Security Review, 65(2), 103-121. https://doi. org/10.1111/j.1468-246X.2012.01430.x

Garzón, E. (2015). Renta Básica, una medida con importantes inconvenientes. Viento Sur, 140 (Junio), 66-72.

Garzón, E. (2016). La Renta Básica Incondicional no es incondicional, digan lo que digan. La Marea, 43, 15-17.

Garzón, E. (2017). Los países que más robots tienen disfrutan de menos paro. $L a$ Marea, 46, 12-14.

Glencore. (2018). The EV revolution and its impacts on raw materials. Glencore, marzo, disponible online en https://iea. blob.core.windows.net/assets/imports/ events/71/Session3Glencore.pdf

Gorle, P., \& Clive, A. (2013). Positive Impact of Industrial Robots on Employment. International Federation of Robotics, Metramartecht, febrero, disponible online en https://robohub.org/wp-content/ uploads/2013/04/Metra_Martech_Study_ on_robots_2013.pdf

Iglesias, J. (2003). Las rentas básicas: el modelo fuerte de implantación territorial. El Viejo Topo: Barcelona.

Jones, S. E. (2006). Against technology: From the Luddites to Neo-Luddism. In Against Technology: From the Luddi- 
tes to Neo-Luddism. Routledge: London https://doi.org/10.4324/9780203960455 Latouche, S. (2006). Le pari de la décroissance. Fayard: París.

Linton, D. (1992). The luddites: How did they get that bad reputation? Labor History, 33(4), 529-537. https://doi. org/10.1080/00236569200890281

Navarro, V. (2018). Las falsedades del supuesto apocalipsis robótico: ¿el fin del trabajo? Blog de Público.es, Disponible online en https://blogs.publico.es/vicencnavarro/2018/05/01/las-falsedades-delsupuesto-apocalipsis-robotico-el-fin-deltrabajo/

Noguera, J. A. (2000). La renta básica y el Estado del Bienestar en España. Revista Internacional de Sociología, 58(26), 65-95.

Noguera, J. A. (2015). ¿Renta básica universal VS. renta garantizada? Algunos mitos y leyendas. Agenda Pública El País, disponible online en http://agendapublica.es/renta-basica-universal-vs-renta-garantizada-algunos-mitos-y-leyendas/

Nübler, I. (2016). New Technologies: A Jobless Future or Golden Age of Job Creation? Working Paper No. 13.

Pérez, C. (2015). Renta Básica Universal: La peor de las soluciones a excepción de todas las demás. Clave intellectual: Madrid.

Pritchett, L. (2020). The future of jobs is facing one, maybe two, of the biggest price distortions ever. Middle East Development Journal, 12(1), 131-156. https:// doi.org/10.1080/17938120.2020.17143 47

Rabeh, M., Arman, H., \& Mousa, S. (2017). The Fourth Industrial Revolution (Industry 4.0): A Social Innovation Perspective. Technology Innovation Management Review, 7(11), 12-20.
Rainie, L., \& Anderson, J. (2017). The Future of Jobs and Jobs Training. Pew Research Center, disponible online en https://www. pewresearch.org/internet/2017/05/03/the-future-of-jobs-andjobs-training/

Red Renta Básica. (2020). ¿Qué es la $R B$ ? Disponible online en http://www.redrentabasica.org/rb/que-es-la-rb/

Stewarts, I., Debapratim, D., \& Cole, A. (2017). Technology and people: The great job-creating machine. Deloitte, disponible online en https://www2.deloitte.com/content/dam/Deloitte/uk/Documents/finance/deloitte-uk-technologyand-people.pdf

Taibo, C. (2019). El decrecimiento explicado con sencillez. La Catarata: BarceIona.

Torres, J. (2019). La renta básica: ¿Qué es, cuántos tipos hay, cómo se financia y qué efectos tiene? Deusto: Barcelona.

World Economic Forum. (2017). The Future of Jobs Report 2018. In Economic Development Quarterly. https://doi. org/10.1177/0891242417690604

Xu, M., David, J. M., \& Kim, S. H. (2018). The fourth industrial revolution: Opportunities and challenges. International Journal of Financial Research, 9(2), 90-95. https://doi.org/10.5430/ijfr.v9n2p90 